\title{
O CONCEITO DE NATUREZA EM LÚLIO E SUA APLICAÇÃO AO SER HUMANO
}

Esteve Jaulent*

SÍNTESIS - Esta comunicación muestra que el pensamiento del filósofo mallorquín avanza con relación al estado de la doctrina tradicional sobre las nociones clásicas de naturaleza y persona porque arranca de su teoría de las Dignidades, según la cual el ser se presenta como actividad formalizada. Si "pensar", "escuchar" y "ver" son actos, lo son por el acto de ser, y tendrá que ser éste, el acto en primer lugar diferenciado. Además, la importante teoría luliana de las obras propias y apropiadas permite una explicación de la naturaleza humana muy consistente con la realidad. Se empieza por explicar cómo surge el hombre por su acto de ser. Según Llull, el hombre radica en el "soy", un "acto común" que conecta alma y cuerpo. La naturaleza humana es la única que reúne en si todo lo criado y es gracias a ella que las criaturas pueden alcanzar su fin. Se demuestra que el alma existe, es criada, y es más por su fin que por su esencia, y es, por consiguiente, eterna. Finalmente, Llull dice que existe en nosotros un entender interior y primigenio, siempre en acto, por medio del cual tenemos noticia de nuestro ser, del ser de las cosas y de Dios.

PALABRAS-CLAVE - Filosofia Medieval. Raimundo Llull. Naturaleza y persona.
ABSTRACT -This communication shows that the thought of the Majorcan philosopher advances in relation to the state of the traditional doctrine on the classic notions of nature and person because it starts up of its theory of the Dignities, according to which the being is presented as formalized activity. If "to think", "to listen" and "to see" $^{n}$ are acts, they are it for the act of being, and it will have to be, the act in the first place differentiated. Also, the important theory Lullian of the own and appropriate works allows an explanation of the human nature very consistent with the reality. It begins explaining how the man arises for his act of being. According to Lull, the man resides in the "I am", a common act that connects soul and body. The human nature is the only one that gathers in itself all that created things and it is thanks to her that the creatures can reach its end. It is demonstrated that the soul exists, it is created, and it is more for its end than for its essence, and it is, consequently, eternal. Finally, Lull says that exists in us internal and primary understanding and always in act, by means of which have our being's notices, of the being of the things and of God. KEY WORDS - Mediaeval Philosophy. Raymond Lull. Nature and person.

A segunda metade do século XX certamente ficará conhecida pelos cultivadores da metafísica como a época em que, pela primeira vez na história da filosofia, se começou a pensar no ser humano como possuidor de um estatuto ôntico diferenciado.

* Instituto Brasileiro de Filosofia e Ciência Raimundo Lúlio (Ramon Llull).

\begin{tabular}{|l|l|l|l|l|l|}
\hline VERTTAS & Porto Alegre & v. 44 & n. 3 & Setembro 1999 & p. 767-780 \\
\hline
\end{tabular}


Karol Wojtila, em seu profundo estudo The Acting Person, ${ }^{1}$ muito embora não tivesse a intenção de desenvolver uma concepção metafísica completa do homem, mostra a pessoa humana sob uma perspectiva bem particular: sua investigação centra-se na pessoa humana enquanto se integra e manifesta a si mesma por meio da ação. O leitor percebe uma clara tentativa de tratar a pessoa humana de forma diferente de como o faz a metafísica clássica. Contudo, como se explica na advertência final, ${ }^{2}$ este aspecto da integração da pessoa na ação apenas nos aproxima a uma especial condição ôntica do homem, mas não a explica suficientemente; e conclui afirmando que a visão do homem que se obtém após a leitura de sua obra parece confirmar, suficientemente, que sua condição ôntica não supera os limites de sua contingência. Isto é, que o homem, ao fim e ao cabo, é um ser. O futuro Papa, portanto, apenas anuncia um estatuto ôntico diferenciado do homem, mas não o define nem o descreve.

Leonardo Polo também desenvolve o tema em sua antropologia transcendental. Segundo esse autor, a essência do homem não é intracósmica, não se assemelha à essência do universo, ${ }^{3}$ se entendermos esta, segundo a tese aristotélica, como a unidade de ordem realizada pelas substâncias que o compõem. Polo explica que o universo como um todo obedece a uma ordem interna, a ordem da causa final. Esse seria o sentido do telos aristotélico. Pois bem, conforme a antropologia aristotélica, o homem é uma substância natural, uma substância vivente, superior, é verdade, às outras substâncias, mas que integra o cosmo junto com elas. A antropologia do Estagirita pára por aí, e o homem resta um ente intracósmico.

Polo vai mais longe, ao afirmar que o homem não está unificado pelo fim do universo, pela unidade de ordem do universo, negando-lhe, por esse motivo, sua condição de ente intracósmico. "O homem pertence ao universo? Não. A interpretação da antropologia como filosofia segunda é rigorosamente a consideração do homem como ser intracósmico, pertencente ao universo. Essa é uma convicção grega, e nela encontra-se a ruptura entre a filosofia cristã e a filosofia grega. A filosofia cristã pode assumir a filosofia grega, mas o que lhe é muito difícil de aceitar é que o homem seja um ser que se explique como pertencente ao universo. Por exemplo, a idéia de que a alma humana é diretamente criada por Deus, tese da filosofia medieval cristã, tira a alma do universo: porque, se tem de ser diretamente criada por Deus, já não a podemos considerar incluída na criação do universo."4 O homem é superior ao universo, explica Polo, porque é uma natureza que se dá a si própria a sua perfeição. O que aperfeiçoa o universo é a causa final, que é extrínseca às substâncias que o compõem. Porém, no caso do homem não é assim. A perfeição do homem é intrínseca: o homem é uma substância capaz de autoperfeição.

1 Karol Wojtyla, Persona y acción, Texto definitivo establecido en colaboración con el autor por AnnaTeresa Tymieniecka, Biblioteca de Autores Cristianos, Madrid 1982.

2

id., id., p. $349-350$

Para o conceito de "essência do universo" em Polo veja-se Curso de Teoria del Conocimiento, v, IV/ $1^{\mathrm{a}}$ parte. Eunsa, Pamplona, 1994.

4 Leonardo Polo, La esencia del hombre, conferência ditada no dia 25/11/1994 na Fac. de Filosofia e Letras da Universidade de Málaga. Cf. os seguintes sites:

http://ensayo.rom.uga.edu/filosofos/Spain/Polo e http://ensayo.rom.uga.edu/antologia/XXE/polo 
Por tratar-se de um ato de ser superior, portador de uma transcendentalidade na qual o ser se converte com o entender e o amar pessoal, Polo confere à essência humana um estatuto superior ao da essência do universo. A essência humana, segundo ele, é aberta, admitindo um crescimento irrestrito. Sempre pode ir além.

Surge, desse modo, uma nova ciência - a antropologia transcendental - legalmente distinta da metafísica, porque seu objeto de estudo, a pessoa humana, é um ser transcendentalmente diferente. A antropologia transcendental não é uma ontologia regional, não estuda o homem como um ente particular ao lado de todos os outros entes, mas como exercendo um ato de ser todo especial, o ato de ser humano.

Talvez essa nova ciência defendida por Polo não chegue a se concretizar, mas não resta dúvida que suas idéias abrem novos caminhos e permitem posicionar devidamente muitos temas humanos. A intelecção, o amor e a liberdade humanos ganham, nessa nova perspectiva, a transcendentalidade que certamente lhes corresponde. Enfim, surge um panorama completamente novo, diante do qual, como diz Salvador Piá, ${ }^{5}$ é difícil ficar indiferente.

Foi precisamente a consideração dessas novas idéias que gerou o presente artigo, mostrando que o filósofo maiorquino Raimundo Lúlio foi também precursor nesses temas. Lúlio (1232-1316) lutou toda a sua vida para tornar conhecido um novo método de ver a realidade, um novo método de pensar - a sua Arte - no qual o ser humano também aparece sob um estatuto ôntico diferenciado.

Estas breves linhas têm o objetivo de mostrar alguns pontos que sinalizam qual era a concepção luliana do homem, baseando-se, principalmente, em duas obras: o Libre de home $e^{6}$ e L Libre de Anima racional ${ }^{7}$ - além, obviamente, de considerar a metodologia implícita na Ars generalis ultima. ${ }^{8}$ Porém, antes será necessário adentrar-se no conceito clássico de natureza, ver como o filósofo maiorquino o utiliza e o aplica ao ser humano.

\section{O conceito clássico de natureza}

Seguindo Aristóteles, a filosofia tradicional sempre entendeu por natureza de uma substância "um princípio intrínseco de movimento". Portanto, a noção de natureza, segundo essa interpretação, terá de ser análoga: algumas vezes será a forma da substância, outras a matéria e, na maioria dos casos, uma vez que princípio e fim se correspondem, a essência - aquilo que se gera - por ser esta o fim dos movimentos naturais de geração. Por esse motivo e de acordo com esta última acepção, Boécio definia a natureza como "a diferença específica que informa qualquer coisa". 9

Salvador Piá Tarazona, La antropología trascendental de Leonardo Polo, Sudia poliana, Pamplona, 1 (1999): 191-15, Cf. na Internet o seguinte site: http://ensayo.rom.uga.edu/filosofos/spain/Polo

Ramon Llull, Libre de Home, ORL XXI, Mallorca, 1950.

Ramon Llull, Libre de Anima Racional, ORL XXI, Mallorca, 1950.

ROL XIV, Brepols 1986.

Para esta questão do conceito tradicional de natureza cf. S. Tomás, S. Theol., III, q. 2. 
Mas é preciso ter cautela ao identificar natureza e essência, pois assim se facilita a confusão entre a ordem real e a ideal. Se por natureza se entende a substância enquanto principio de operações, não se deveria identificar natureza com essência, pois esta última não é um princípio do operar da substância, mas apenas a explicação do porquê de a substância operar naturalmente de uma determinada maneira. Tenha-se em conta que a essência expressa, num ente concreto, as razões do ato de ser desse ente ${ }^{10} \mathrm{e}$, portanto, pertence a uma ordem distinta do ser. ${ }^{11}$ A essência é abstrata; o existente, concreto. Apenas quando se considera que o ente existente concreto participa do ser na medida indicada pela essência, é que se pode admitir que essa essência não seja abstrata mas atual. Desse modo, a essência, nesse ente concreto atual, distingue-se realmente do ato de ser desse ente. Nesse caso, para referir-se a ela é melhor utilizar o termo natureza em vez do termo essência e dizer, com S. Tomás, que "o existente é uma natureza que participa do ser". ${ }^{12}$

Natureza e substância também não são a mesma coisa. Como se viu, natureza acrescenta à noção de substância a nota "princípio de operações". Portanto, se existir uma substância que não seja causa, isto é, um mero efeito, essa substância não será uma natureza. Aristóteles não admitia isso porque a sua interpretação da substância era causal. Na sua opinião, todas as substâncias reduziam-se a causas. ${ }^{13}$ Mais estritamente ainda, a diferença entre substância e natureza deve ser buscada na relação de ambas com 0 ato de ser. $\mathrm{E}$, assim, deve dizer-se que a' substância tem, ou exerce, 0 ato de ser; ao passo que a natureza segue 0 ser como algo resultante dele. ${ }^{14}$

Uma vez esclarecida a noção de natureza e comparada com as noções de substância e essência, pode-se sintetizar a doutrina tradicional da seguinte maneira: uma substância particular que seja causa, que opere, sempre existirá numa natureza, isto é, além de ser, terá naturalmente algumas operações próprias dela; por sua vez, a operatividade natural dessa substância será delimitada por sua essência. Com outras palavras, relacionando mais uma vez as três noções que se acabam de estudar e tendo também presente que sempre se opera por um fim e que o fim das coisas é dado pelo que elas são, isto é, pela essência, pode-se dizer que a substância se relaciona mediante a natureza com o fim que lhe é proposto pela essência.

${ }^{10}$ Cf. S. Tomás, De Verit., q. 21, a. 1: "In quolibet autem ente, est duo considerare: scilicet ipsam rationem speciei, et esse ipsum quo aliquid aliud subsistit in specie illa."

11 A essência - termo geral que indica o que os entes são - é o constitutivo inteligivel do ente - ipsam rationem speciei. Como os entes se colocam pelas suas naturezas nos diversos ge̊neros e espécies, é a essência, significada pela definição, é a explicação inteligível daquilo que o ente é. Cf. S. Tomás, Ad Colossenses, n. 30: "aliquam naturam participantem esse".

Leonardo Polo, La esencia del hombre, veja-se nota 4.

14 Cf. S. Tomás, S. Theol., III, q. 17, a. 2, ad 1: "Dicendum quod esse consequitur naturam, non sicut habentem esse, sed sicut qua aliquid est; personam autem sive hypostasim consequitur sicut habentem esse." 


\section{A natureza da pessoa humana na filosofia tradicional}

Recordando brevemente a doutrina tradicional sobre a pessoa, deve-se dizer que, quando existe de uma maneira completa, uma substância particular é chamada de hipóstase, suposto ou subsistência concreta. A mão ou o pé, por exemplo, embora sejam substâncias particulares, como não subsistem por si mas existem num ser mais completo, não são supostos. Pois bem, ao suposto convém existir sempre nalguma natureza, e, se essa natureza é a natureza racional, o suposto é chamado de pessoa. Como diz S. Tomás, ${ }^{15}$ a "pessoa acresce ao suposto uma natureza determinada, a natureza racional".

À pessoa são atribuídas as operações e as propriedades da essência e tudo quanto pertence à natureza. Por exemplo, este homem é uma pessoa porque supõe tudo o que pertence ao homem que, por conseguinte, se predicará deste homem.

Porém, deve-se levar em conta que, embora exista a idéia ou conceito de pessoa, é preciso ter cautela com a definição de pessoa, pela simples razão de que a noção de pessoa não é uma espécie. Como é sabido, as definições realizam-se acrescentando ao gênero uma diferença específica, o que não pode ser feito no caso da pessoa, pois ela não é uma espécie do gênero indivíduo. Justamente por isso, S. Tomás ampliou a definição de pessoa dada por Boécio - substância individual de natureza racional - entendendo pelo termo substância não o gênero predicamental substância, mas o ente concreto individual subsistente. ${ }^{18}$

Se a definição expressa sempre a essência de uma espécie, a noção de pessoa não poderá ser definida, pelo simples motivo de não ser uma espécie. Conseqüentemente, não deve ser incluída em nenhum dos modos do ente predicamental. Se a pessoa fosse incluída nalgum deles, não se estaria concebendo a pessoa segundo a sua própria razão de ser. ${ }^{17}$ Do ponto de vista do ser, cada pessoa constitui um grau de perfeição na participação do ser. O ato de ser de cada pessoa é, pois, o seu constitutivo metafísico assim como a origem e raiz de todas as propriedades e perfeições pessoais. ${ }^{18} \mathrm{O}$ nome pessoa é, pois, quase um nome próprio.

É nesse ponto que começa a aparecer o estatuto especial da pessoa humana. Cada pessoa é um existente concreto, do qual se sabe que existe numa natureza racional concreta, natureza que, por sua vez, é um resultado do ato de ser da pessoa e que não possui a razão de espécie. Portanto, convém que cada pessoa seja concebida como diretamente participante do ser. Desse modo, seus limites, no ser e no operar, não são fixados por uma suposta "espécie pessoa" mas, exclusivamente, pela natureza racional na qual subsistem. Daí a importância de compreender-se bem essa natureza.

15

16

17 Cf. Francesc Canals Vidal, Sobre la esencia del conocimiento, PPU, Barcelona, 1987, p. 582, n. 1.

Cf. Eudaldo Forment, La persona humana, em El pensamiento de Santo Tomás de Aquino para el hombre de hoy, Abelardo Lobato, Armando Segura e Eudaldo Forment, Edicep, México, Santo Domingo, Valencia 1994, p. 748. 
De modo diverso ao dos entes que não são pessoas - que participam do ser na medida indicada por sua essência; classificam-se, justamente por essa medida, num dos modos do ente predicamental, e se aperfeiçoam também segundo a sua essência, isto é, segundo aquilo que são - as pessoas aperfeiçoam-se constantemente, segundo os parâmetros de sua natureza racional e exclusivamente por causa disso, adquirindo a perfeição dos outros entes, tornando-se possivel até que, numa única pessoa, se concentre toda a perfeição do universo. ${ }^{19}$ Realizam essa possibilidade por meio de seus atos de conhecimento e de amor.

Para um bom entendimento da noção de natureza, torna-se necessário advertir que dentro do tomismo existem diversas posturas filosóficas ${ }^{20} \mathrm{com}$ relação ao ente, o que em muitos casos pode conduzir a conclusões quase contrárias em diversos temas. Essas correntes poderiam ser classificadas em dois grandes grupos: as essencialistas e as filosofias denominadas do ser, estas últimas interpretando, segundo parece, mais fielmente o pensamento do próprio S. Tomás.

Mais aristotélicos que os partidários da filosofia do ser, os essencialistas concedem, na constituição do ente, um maior peso à essência do que ao ser. Isso os obriga a atribuir mais importância aos conteúdos abstratos que ao ente concreto. Pode-se dizer que os essencialistas contemplam tudo mediante o conceito, uma vez que na sua opinião a clareza conceitual é mais importante que a realidade em si. Obviamente, isso não deixa de ter conseqüências em diversos campos. $\mathrm{Na}$ teoria do conhecimento, por exemplo, o juízo verdadeiro, expressão de um entendimento verdadeiro, é mais importante que o próprio entendimento verdadeiro. Ainda nesse campo, é fácil encontrar essencialistas defendendo a existência de um conceito de ser. Em metafísica - o campo do presente trabalho - tendem a fixar as naturezas dentro de dimensões imóveis, desse modo justificando mais facilmente um valor universal das leis. Muitas outras conseqüências poderiam ser apontadas, todavia, para o que diz respeito a estas linhas, vale constatar apenas que, na teologia, os essencialistas separam a ordem natural da sobrenatural de forma absoluta, devido justamente à sua tendência a considerar todas as coisas por intermédio de seus conceitos. E, de fato, os conceitos separam o que na ordem real se encontra unido.

De modo diverso, as filosofias do ser ressaltam o ser "dentro" do ente. De fato, dão um passo à frente em relação a Aristóteles, pois o Estagirita não chegou a afirmar claramente a distinção entre ato de ser e essência, devido a que utilizou sua teoria do ato e da potência para explicar o movimento, mas não para explicar a estrutura do ente. Sob a luz das filosofias do ser, visualiza-se melhor essa distinção real. Além do mais, as filosofias do ser privilegiam o concreto sobre o abstrato. Têm mais presente que antes de 0 entendimento expressar uma verdade por meio de um juízo, essa verdade já se encontra no entendimento, embora não o saibamos. Portanto, segundo essas filosofias, a verdade, após uma simples apreensão e

${ }^{19}$ Cf. Jaime Bofill Bofill, La escala de los seres, Publicaciones "Cristiandad", Barcelona 1950, p. 97.

${ }^{20}$ João Paulo II em sua encíclica Fides et ratio, n. 58, fala de diversas escolas tomistas: "São conhecidas as felizes consequiências que teve este convite pontifício. Os estudos sobre o pensamento de $\mathrm{S}$. Tomás e doutros autores escolásticos receberam novo incentivo. Foi dado um forte impulso aos estudos históricos, de que resultou uma nova descoberta das riquezas do pensamento medieval, até então amplamente desconhecidas, e constituiram-șe novas escolas tomistas." 
antes do juízo, já se encontra materialmente no entendimento que, por essa razão, é chamado de verdadeiro. As conseqüências desse modo de ver as coisas são realmente importantes. Em teoria do conhecimento enfatiza-se a autoconsciência: uma notícia do ser da própria pessoa que conhece, durante 0 ato de conhecer. Ainda nesse campo, se bem se considere que os universais são reais, lembra-se insistentemente que lhes foi conferida a sua universalidade por um ato do entendimento e, assim, privilegia-se claramente o concreto sobre o abstrato. Em metafísica, a transcendência de Deus, ato puro de ser, resulta mais evidente, pois as criaturas serão sempre compostas de ato de ser e de potência. Devido a que o ser, e não a essência, é o princípio que fundamenta o ente, encontra-se também mais facilidade em admitir flexibilidade às naturezas, uma vez que estas são as substâncias consideradas como principio das operações. Em teologia, a separação absoluta entre a ordem sobrenatural e a natural desaparece, pois se admite uma abertura da razão para a ordem sobrenatural. ${ }^{21}$

Uma vez revistos os conceitos clássicos de natureza, pessoa e tendo advertido sobre os diferentes modos de enfocá-los, podemos agora apresentar o pensamento de Raimundo Lúlio sobre o conceito de natureza humana.

\section{Ser, essência e natureza em Lúlio}

Lúlio aprofunda e avança com relação ao estado da doutrina a respeito dos conceitos clássicos de ser, essência e natureza. Segundo o maiorquino, todo ente é constituído de princípios transcendentes, uns absolutos e outros relativos, ativos - as dignidades - que se contraem dum modo natural, de acordo com a medida dada pela própria essência, ${ }^{22}$ para desse modo constituir o ser daquele ente concreto. Em Lúlio, portanto, também se encontra a distinção real entre essência e ser.

As dignidades esclarecem em que consiste a perfeição do ato de ser: elas são ativas e, como todos os atos, têm seus três correlativos "ato", "potência" e "objeto", sem os quais nenhum ato seria possivel. ${ }^{23}$ Não existe o "entender" sem o "inteligivel" e o "entendido", o mesmo ocorrendo com todos os outros atos, quer sejam atos constitutivos das diversas substâncias, quer os atos realizados por elas uma vez já constituídas. Em Deus - Ato puro de ser - esses princípios transcendentes apresentam-se numa modalidade divina, infinita, conversiveis cada um deles com a Essência divina, a qual também é conversivel com o Ser divino. Isso

${ }^{21} \mathrm{~S}$. Tomás chega a dizer que Deus abriu o entendimento a alguns homens - os Apóstolos - com a finalidade de que entendessem as Escrituras. Cf. Ad Hebreos, n. 408: "[...] sed tantum de primis fundatoribus Novi Testamenti, scilicet Apostolis, qui immediates fuerunt instructi a Deo, quando aperuit illis sensum., ut intelligerent scripturas. Apostoli ergo facti sunt perfecte cognoscentes, et non ab aliis instructi, sed simul a Christo acceperunt sapientiam infusam."

22 Cf. Ramon Llull, Lógica nova, Neorl IV, p. 72: "Essencia es alcuna cosa confusa consirada, per la qual esser es estant, quar aixi con bon es concret de sa bontat, que es la sua essencia, axí esser es concret de sa essencia." As essências também estão constituídas pelos princípios transcendentes, mas considerados em abstrato. Ao contraírem-se no ente concreto, estes princípios ganham diferenças concretas entre si.

23 Para um estudo histórico sobre a formação da teoria dos correlativos em Lúlio, cf. Jordi Gayà Estelrich, La teoria luliana de los correlativos, Palma de Mallorca, 1979. 
não ocorre nas criaturas, pois nelas não se dá a identificação entre ser e essência, uma vez que o ser se contrai em seus principios segundo a positividade da própria essência. Como Lúlio explica isso?

As essências de cada ente, informa o Doutor Iluminado, "contraem-se no seu sujeito natural e coessencial consigo mesmo, graças à sua natureza; e esse mesmo sujeito é reduzido, ou contraído, ao seu ato natural, também por sua natureza". ${ }^{24}$

Essa descrição é muito rica. Sua novidade radica em que o ser é apresentado como atividade formalizada. De fato, parece que deve ser assim, pois os atos sempre ocorrem diferenciados internamente. Se "pensar", "escutar" e "ver" são atos, eles o são pelo ato de ser, e é este, o ser, o ato que em primeiro lugar deve estar diferenciado. Não se deve pensar o ser como se fosse uma energia absolutamente indeterminada. O ser é um oceano de perfeições porque engloba todas elas, ${ }^{25}$ ou seja, engloba as Dignidades.

As dignidades contraem-se ao constituir o ente finito. É a essência que indica as dimensões e a mistura - mixtio - dos princípios transcendentes que se dá no ente concreto. A essência é, por si mesma, algo abstrato - consideratum, consirada - todavia, por sua natureza, se torna concreta no ente. A essência está também constituída pelos princípios transcendentes, mas considerados em abstrato. Explica o maiorquino que é devido à natureza da essência, que esses princípios se contraem no ente concreto, surgindo, desse modo, nesse ente concreto, as diferenças concretas entre os princípios. É, pois, graças à natureza da essência, que o ser do ente é estável.

Segundo Lúlio, a natureza situa-se entre o ser e a essência. ${ }^{26} 0$ conceito de natureza era tão importante para o maiorquino que foi selecionado na sua Logica nova para exemplificar como se aplica o método das dez perguntas gerais, seguido na Ars. Lá se diz que a natureza é ativa e que não pode haver natureza sem ato próprio. Explica-se que é pela natureza que o ser e a essência participam entre si; que, graças aos seus correlativos, a natureza pode relacionar-se com outros entes que não são de seu gênero; que, no sujeito onde radica, é o seu agente natural ativo, podendo "naturar"; mas que é também potência passiva, sendo receptiva dos outros entes que nela são "naturados"; que a natureza, no sujeito em que é, tem seu ser e seus princípios, dos quais é; e seu sujeito tem tal natureza, enquanto é por ela "naturado". Enfim, inúmeras respostas às perguntas "de que?, por quê?, quanta?, qual?, quando?, onde?, de que modo?, com quê?", que o breve espaço a que têm direito estas linhas não permite expor.

Contudo, para finalizarmos esta parte, convém ainda fazer duas observações. Em primeiro lugar, que a natureza, segundo o maiorquino, é do suposto no qual existe, o qual atua naturalmente por ela, movendo-se e repousando no seu ser e no seu agir por entre coisas naturais. Doutrina essa que coincide com a clássica.

Cf. Raimundus Lullus, Lògica nova, Felix Meiner Verlag, Hamburg, 1985, p. 70: “[...] quoniam essentia per suam naturam contracta est ad suum subiectum naturale, sibi coessentiale; et ipsum subiectum per naturam se contrahit ad actum naturalem"

26

Cf. Jesús de Garay, Los sentidos de la forma en Aristóteles, Eunsa, Pamplona 1987, p. 150.

Cf. Ramon Llull, Lògica nova, NEORL IV, p. 72: "Natura es ens que propriament està entre essencia e esser egualment." 
Em segundo lugar, destacar a importante teoria luliana sobre as obras naturais próprias e apropriadas. Como se disse anteriormente, o suposto é reduzido, ou contraído, pela natureza, ao seu ato natural. Lúlio insiste muito em que as substâncias possuem uma atividade própria e outra apropriada. A primeira é substancial e se converte, no sujeito onde tem lugar, com a sua forma; ${ }^{27}$ a segunda, chamada "ação acidental", converte-se com a forma acidental. A ação substancial é essencialmente contínua ${ }^{28}$ e sempre atual. A ação apropriada é acidental e artificial, move-se sempre da potência ao ato, e sua finalidade é a ação natural. ${ }^{29}$ Obviamente, essas noções serão fundamentais na explicação da natureza humana.

\section{A natureza humana}

Antes de mais nada, convém recordar que Lúlio não apenas confere um estatuto diferenciado ao homem, mas a nove sujeitos distintos - Deus, os anjos, os corpos celestes, o homem, o mundo sensível, o mundo vegetal, o mundo dos elementos e o mundo artificial - nos quais, nas suas palavras, "está implicado tudo o que é".$^{30}$ Não se trata, portanto, de uma classificação segundo as categorias predicamentais, mas segundo o grau de participação no ser e resultante das dignidades.

Lúlio explica o ser humano dizendo que se trata de um todo constituído por três partes. A primeira é formada pelos correlativos ativos da alma e do corpo, que se reagrupam e ajustam uns aos outros, constituindo a "forma comum" do homem. A segunda, é formada pelos correlativos passivos da alma e do corpo que, reagrupando-se e ajustando-se, constituirão a "matéria comum" do homem. Finalmente, do agrupamento e ajustamento de todos os atos da alma e do corpo, resulta a terceira parte, um "ato comum", por meio do qual e no qual e com o qual a matéria e a forma se conectam, resultando da união dos três - ato, matéria e forma - o homem. Sem este ato, não haveria nem matéria nem forma. Dessa maneira, surge o homem pelo ato de ser: o homem radica no "sou". "E en així home està en lo som", diz Lúlio. ${ }^{31}$

Observe-se que as três partes em conjunto constituem o "ser" do homem. Não se está falando da essência, mas do ato de ser humano. No lulismo, todo ato é tridimensional e, desde suas primeiras obras, Lúlio significou essas três dimen-

${ }^{27}$ Cf. Lógica nova, NEORL IV, p. 51: "Si acció e forma se convertexen en lo subjet en que son. E responem d[i]visén, so es que es acció primitiva e acció secundaria. Primitiva es substancial o substantiva qui ab si matexa e ab la sua propria materia constituex substancia general, constituida de forma e de materia substancial. E aytal acció es dita esser convertida ab la sua forma. Enperó la acció secundaria que es actus de la primera forma, en genre de accident posada, ab forma accidental se convertex, axí con calor que.s convertex ab la sua acció, so es ab la sua activitat."

Cf. id., NEORL IV, p. 52.

Cf. Libre de Home, ORL XXI, p. 42.

30 Cf. Raimundus Lullus, Ars Generalis ultima, ROL XIV, p. 189: "Ouoniam in novem subiectis omne, quod est, implicatur, et extra ea nihil est, idcirco volumus ponere ipsa in hac Arte, ut cum ipsis Ars sit generalis."

3

Cf. Libre de Home, ORL XXI, p. 28: "E açò mateix dels actus de 1 ànima e del cors, qui sajusten, e de lur conjunyiment e ajustament resulta e hix home qui passa e està en terç nombre, e és lo tot simple en nombre de home, segons sa diffinició, e ses parts són la sua forma comuna e matèria comuna e l actu comú que dit havem. E en axi home està en lo som." 
sões do ser com os termos "forma", "matéria" e "conexão". Em 1300, ano em que escreveu o Libre de Home, ainda utilizava esses termos que, poucos anos depois, foram substituídos por outros: os termos "potência", "objeto" e "ato".$^{32}$ Portanto, não se deve confundir a "forma comum" de homem, aqui referida, com a alma, nem a "matéria comum" com o corpo. São a forma e a matéria comum do homem as que, ao coligarem-se pelo ato, originam o homem. Lúlio estudará separadamente a alma em muitas de suas obras, especialmente no Libre d'Anima racional, e o corpo, no Libre de Home, explicando em que consiste cada uma dessas outras partes do homem.

E qual será esse "ato comum" sem o qual o homem deixa de ser homem? Pois o ato conjunto de "entender, querer, lembrar, elementar e vegetar, sentir e imaginar, sem o quais o homem não seria conexo substancialmente ${ }^{n} \cdot{ }^{33}$ Não resta dúvida de que, de acordo com isso, fica bem mais fácil de compreender que o homem desaparece não só quando se destrói o seu soma, mas também quando deixa de amar ou de pensar.

Lúlio explica a natureza humana pela "forma comum" e a "matéria comum" do homem..$^{34}$ A primeira agrupa, como se viu, os correlativos ativos do corpo e da alma, e a segunda os correlativos passivos também de ambos. Por conseguinte, para entender bem a natureza humana, será necessário estudar o corpo e a alma humanos que se conectam justamente pelo "ato comum" que origina o homem.

No corpo humano têm parte todas as criaturas corporais. Por causa disso, Deus criou a alma racional para que, unida ao corpo humano, originasse o homem e nele todas as criaturas corporais alcançassem o fim para que foram criadas. ${ }^{36} \mathrm{~A}$ natureza humana, portanto, é a única que reúne em si mesma tudo quanto é criado e, graças a ela, as criaturas corporais podem alcançar seu fim em Deus e nEle repousar.

Está implícito nesse argumento que Deus criou as substâncias corporais para Si próprio e portanto que Ele é o fim das mesmas. Todavia, para que este fim se realize, torna-se necessário que exista um ente que com seu entendimento conheça tanto as coisas corporais como o próprio Deus, e que ao mesmo tempo esteja unido a um corpo. Esse ente é o homem, instrumento para o fim e o repouso das criaturas corporais.

Segundo esta doutrina, o mundo foi criado para ser "pensado" pelo homem. Tudo é inteligivel e nada é supérfluo, desde a menor molécula do corpo humano até a ínfima partícula material. Lúlio faz retornar o mundo criado para Deus através do homem e é a favor de uma salvação que se leva a termo segundo dimensões humanas, incluindo a completa restauração do aspecto corporal e terreno do homem.

32

33

34

35
Cf. Jordi Gayà Estelrich, La teoria luliana de los correlativos, Palma de Mallorca, 1979, p. 224.

Cf. Raimundus Lullus, Ars Generalis ultima, ROL XIV, p. 234: "Es istud medium connaturale est intelligere, velle et recolere, elementare et vegetare, sentire et imaginari, sine quibus homo non esset coniunctus substantialiter. Et tamdiu vivit homo, quamdiu ista naturalis coniunctio durat in eo." Cf. Raimundus Lullus, Logica nova, Felix Meiner Verlag, Hamburg, 1985, p. 276: "Natura formaliter est, quia est ex naturali forma et materia." É a definição formal geral para todas a naturezas.

Cf. Raimundus Lullus, Libre de Anima racional, ORL, XXI, p. 167. 
A alma racional existe, e Lúlio demonstra isso de diversas maneiras. "Somente o homem realiza ações contra a natureza, pois nenhum animal irracional se mata, enquanto alguns homens se suicidam [...] Convém, pois, que haja no homem alguma substância mais alta que a substância dos irracionais e que não seja da essência corporal pois, se o fosse, obedeceria à natureza e aos modos dos irracionais. Chamamos a essa substância alma racional." ${ }^{36}$

Como Lúlio é realista, só compreende a natureza humana por meio das modalidades de sua experiência vital. De acordo com seu modo habitual de proceder, sempre parte do ser para explicar a coisa. Assim, esse realismo leva-o a afirmar que a alma humana é criada, o que demonstra de dez formas diferentes. A primeira razão que apresenta é o fato de a alma humana ser livre. Se fosse gerada, explica, não teria liberdade, pois se dirigiria para seus objetos de uma maneira natural e não livre, semelhante aos olhos que, naturalmente, atingem as cores. Diferencia-se, pois, da alma sensitiva animal, que é gerada e ganha sua natureza dos genitores. ${ }^{3}$

Lúlio pensa que tudo quanto é natural se origina por geração e se corrompe. A natureza fornece ao ente natural, e a seus atos, certos limites ou termos, além dos quais não pode ir e dentro dos quais encontra repouso. Os poderes da natureza são, pois, limitados. Além disso, todo ente natural se corrompe.

Mas isso não se aplica à alma humana. Se a alma humana fosse gerada, nasceria de corrupção e envelheceria, pois nenhuma coisa gerada na terra pode nascer e ser sem levar-se em conta a corrupção dos outros entes dos quais é. Curvando-se ao seu realismo, Lúlio explica que a alma racional é criada porque não envelhece, nem é afetada pela velhice do corpo, o que se pode constatar ao ver que o homem sábio, velho, tem mais ciência do que quando jovem. ${ }^{38}$

O maiorquino tira inúmeras conseqüências disso. Afirma que a alma racional é mais pelo seu fim que pela sua essência ${ }^{39}$, explicando-o da seguinte maneira: algo é por essência quando é pelos seus princípios naturais; todavia, como a alma racional é criada, o seu fim é Deus, que está acima de seus princípios naturais, e só em Deus encontrará repouso.

O fim é um dos princípios transcendentes que constituem o ser de todas as coisas. Ora, o fim da alma a que se refere Lúlio, quando afirma que "a alma é mais pelo seu fim que pela sua essência", é o fim de Deus. Deus criou a alma para que o homem $\mathrm{O}$ conhecesse e $\mathrm{O}$ amasse. Assim sendo, se a alma fosse mais pelo que é que pelo seu fim, seu ser seria mais nobre que o ato ${ }^{40}$ de amar e conhecer Deus. Mas isso é impossivel, pois nenhuma substancia que provenha do nada pode encontrar repouso em si mesma. A alma racional é, conclui o maiorquino, principalmente por razão do fim de Deus e não por razão de si mesma, tal como o martelo, que é pelo fim do prego e não por seu próprio fim. ${ }^{41}$

36 id., p. 169.

id. p. 174.

38 id, id.

39 Cf. Libre de Anima racional, ORL, XXI, p. 171.

40 Sobre a unificação universal pelo ato no pensamento luliano, cf. Breu consideració sobre la regla $B$ de l'Ars lulliana, Revista Internacional de Humanitats, USP-Univ. Autònoma de Barcelona (1999), 3

41. $\mathrm{p}$.

Cf. Libre de Anima racional, ORL, XXI, p. 171. 
Por ser mais pelo fim que por si mesma, a alma é eterna, ${ }^{42}$ e é conservada ${ }^{43}$ por esse fim, e não pode deixar de ser, assim como o copo de vinho que um homem sustenta com sua mão para beber. Enquanto queira beber, isto é, estando conforme o fim, o copo não pode cair; embora, por ser algo pesado, possa cair ao chão por si mesmo. ${ }^{44}$

Por não ter seu fim neste mundo, este não a pode satisfazer; coisa comprovada pelo fato de que constantemente o homem deseja entender mais, amar mais e lembrar mais o que já entende, ama e recorda. Se a alma racional fosse gerada, seus atos teriam limite e encontrariam repouso dentro desses limites e dentro dos poderes que os primeiros pais the tivessem conferido. ${ }^{45}$

Finalmente, lembra que é pela alma que a natureza humana é mais nobre que a animal. Por isso, a natureza atua com maior força no corpo humano que no corpo dos animais - natura ha major virtut en cors humà que en cors bestial. ${ }^{46}$ Muitas conseqüências poderiam ser tiradas ainda dessa racionalidade que impregna também todos os movimentos corporais do homem e todos seus sentimentos.

\section{Os hábitos substanciais}

Um tema que se tornou polêmico nos tempos do maiorquino foi o das potências da alma. Opinavam alguns que a inteligência, a vontade e a memória não constituiam parte da substância racional, mas seriam apenas potências acidentais. A Ars luliana demonstra incontestavelmente que o entendimento, a memória e a vontade são partes substanciais da alma. Se não fossem da essência da alma, "Deus non est materialiter intelligibile, diligibile, nec aliquid perfectum"."

Lúlio dirá que os diversos atos de conhecimento, lembrança e amor, que o homem realiza, são sustentados por um entender, um lembrar e um amar substanciais que se encontram sempre em ato no homem. Esta afirmação é conseqüência de sua teoria das obras naturais e apropriadas exposta acima. Lúlio atribui às substâncias uma atividade própria e outra apropriada. A primeira é habitual; a segunda tem como finalidade a primeira.

Assim, por exemplo, o objeto próprio do entendimento - que se corresponde com seu ato próprio - é entender sua inteligibilidade e intelectualidade. Como a alma racional, por ser criada, vive vida espiritual e não depende de outras partes corruptíveis, o entendimento não cresce nem se multiplica por seus atos apropria$\operatorname{dos}^{48}$ e pode viver de sua vida ou atividade natural própria, que consiste em entender-se.

${ }^{42}$ Cf. Libre de Ànima racional, ORL, XXI, p. 172.

id. p. 182.

id. p. 170.

Cf. Libre de Anima racional, ORL, XXI, p. 175.

Cf. Libre de l'Orde de cavalleria (A cura d'Albert Soler i Llopart), Editorial Barcino, Barcelona 1988, III, 10, 80, p. 192.

47 Sobre este tema, sobre o qual existia uma "diabólica disputatio", cf. J. N. Hillgarth, Ramon Llull i el naixement del lul.lisme, Publicacions de l'Abadia de Montserrat, Barcelona 1998, p. 266, n. 172.

48 Cf. Libre de Ánima racional, ORL, XXI, p. 179 e 183. 
A novidade é importante, pois se declara que existe no homem um entender interior e primigênio, por meio do qual tem notícia de seu ato próprio, isto é, de seu ser. Lúlio afirma que existe no homem um nivel interior de conhecimento, no qual tem lugar também a notícia dos atos de ser dos entes que conhece e, sobretudo, a notícia primordial do Ser Supremo, do qual todos dependem. Essa nova instância de conhecimento, procurada durante séculos pela filosofia, terá tanta importância que deveria ser para alguns o ponto de partida do filosofar. No fundo, trata-se de um conhecimento pelo qual se julga o conhecimento objetivo das operações de conhecer. Schelling, por exemplo, indicava a necessidade daquilo que denominava "êxtase da razão", isto é, o "situar-se fora de si mesmo" ou, mais exatamente, fora da razão, para o conhecimento humano poder alcançar o Absoluto. $^{49}$

Por outro lado, ao afirmar que o fim dos outros atos de conhecer, mediante os quais se conhecem os outros seres, é sempre esta atividade própria do entendimento mediante a qual o entendimento se autoconhece, Lúlio destaca a dimensão existencial do conhecer humano, cujo fim é sempre a própria pessoa.

Algo semelhante ocorre com os atos próprios da memória e da vontade. Repare-se que a atividade substancial se converte com a própria substância. São hábitos substanciais, sempre em ato, e podem aumentar constantemente no homem. Mais ainda, sem eles, o homem não poderia existir. Impressiona a forma como Lúlio afirma isso: "Se não houvesse na memória um contínuo lembrar, e, no entendimento, um contínuo entender, e, na vontade, um contínuo querer, as formas e as matérias espirituais da alma seriam ociosas e não teriam como se ajustar, e dado que as formas não teriam ação nem as matérias, paixão, sem esse radical lembrar, entender e querer, a alma não teria como informar o corpo nem com que dar-lhe o ser e a vida, e não se poderia ajustar nem coligar com ele. Convém, pois, que os radicais lembrar, entender e querer estejam em contínuo ato tudo o tempo em que o homem é homem". ${ }^{50}$ Lúlio faz depender o próprio ser do homem desses atos radicais de entender, lembrar e amar, que alimentam a sua própria substância e a aperfeiçoam. Caso pudéssemos libertar-nos deles, aniquilaríamos o homem.

Essa concepção luliana da natureza humana abre perspectivas extraordinárias. Distingue claramente, pela autoconsciência, o homem do animal. Aponta a origem da consciência religiosa, que aparece em todas as épocas da humanidade. E mostra as infinitas possibilidades de crescimento do ser humano.

49 Cf. F. W. J. Schelling, Initiae Philosophiae Universae, Erlanger Vorlesungen 1820/21, org. H. Fuhrmans, Bonn; H. Bouvier u. Co. Verlag, 1969, p. 39, citat per Fernando Rey Puente, Algumas notas sobre o conceito de "enérgeia" como eixo da articulação entre a filosofia negativa e a filosofia positiva no pensamento tardio de Schelling, Síntese Nova Fase, Belo Horizonte, v. 22, n. 70, 1995, p. 396 Cf. Libre de Home, ORL XXI, p. 35. 